\title{
GATA5 loss-of-function mutation in familial dilated cardiomyopathy
}

\author{
XIAN-LING ZHANG $^{1 *}$, NENG DAI $^{1 *}$, KAI TANG $^{1}$, YAN-QING CHEN $^{2}$, WEI CHEN $^{1}$, JUAN WANG $^{3}$,

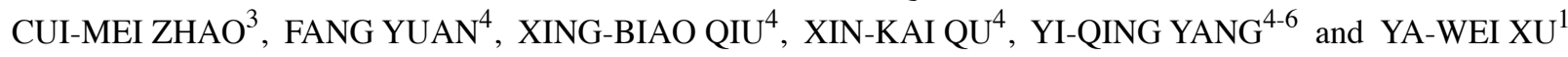 \\ Departments of ${ }^{1}$ Cardiology and ${ }^{2}$ Emergency Critical Care Medicine, Shanghai Tenth People's Hospital, \\ Tongji University School of Medicine, Shanghai 200072; ${ }^{3}$ Department of Cardiology, Tongji Hospital, \\ Tongji University School of Medicine, Shanghai 200065; Departments of ${ }^{4}$ Cardiology and ${ }^{5}$ Cardiovascular Research, \\ and ${ }^{6}$ Central Laboratory, Shanghai Chest Hospital, Shanghai Jiao Tong University, Shanghai 200030, P.R. China
}

Received October 8, 2014; Accepted December 22, 2014

DOI: $10.3892 / \mathrm{ijmm} .2014 .2050$

\begin{abstract}
Dilated cardiomyopathy (DCM), the most common form of primary myocardial disease, is an important cause of sudden cardiac death and heart failure and is the leading indication for heart transplantation in children and adults worldwide. Recent studies have revealed a strong genetic basis for idiopathic DCM, with many distinct genes causally implicated. Nevertheless, DCM is a genetically heterogeneous disorder and the genetic determinants underlying DCM in a substantial proportion of patients remain unclear. In this study, the whole coding exons and flanking introns of the GATA binding protein 5 (GATA5) gene, which codes for a zinc-finger transcription factor essential for cardiovascular development and structural remodeling, were sequenced in 130 unrelated patients with idiopathic DCM. The available relatives of the index patient carrying an identified mutation and 200 unrelated ethnically matched healthy individuals used as the controls were genotyped for GATA5. The functional characteristics of the mutant GATA5 were analyzed in contrast to its wild-type counterpart by using a dual-luciferase reporter assay system. As a result, a novel heterozygous GATA5 mutation, p.G240D, was identified in a family with DCM inherited in an autosomal dominant pattern, which co-segregated with DCM in the family
\end{abstract}

Correspondence to: Professor Ya-Wei Xu, Department of Cardiology, Shanghai Tenth People's Hospital, Tongji University School of Medicine, 301 Yanchang Road, Shanghai 200072, P.R. China E-mail: xuyawei69@163.com

Professor Yi-Qing Yang, Department of Cardiology, Shanghai Chest Hospital, Shanghai Jiao Tong University, 241 West Huaihai Road, Shanghai 200030, P.R. China

E-mail: yang99yang66@hotmail.com

*Contributed equally

Key words: dilated cardiomyopathy, genetics, transcription factor, GATA5, reporter gene with complete penetrance. The missense mutation was absent in 400 reference chromosomes and the altered amino acid was completely conserved evolutionarily across species. Functional analyses revealed that the GATA5 mutant was associated with significantly diminished transcriptional activity. This study firstly links GATA5 mutation to DCM, which provides novel insight into the molecular mechanisms of DCM, suggesting a potential molecular target for the prenatal prophylaxis and allele-specific treatment of DCM.

\section{Introduction}

Dilated cardiomyopathy (DCM) is a progressive myocardial disease of unknown etiology characterized by left ventricular dilation and contractile dysfunction with normal ventricular wall thickness (1). It is the most common type of primary cardiomyopathy, with an estimated prevalence of 1 in 2,500 individuals (1). DCM may lead to ventricular systolic dysfunction and progressive heart failure, ventricular and supraventricular arrhythmias, conduction system anomalies, thromboembolic events and sudden cardiac death (1-5). Indeed, DCM is the third most common cause of heart failure and the most frequent reason for heart transplantation (1). A broad range of acquired causes have been implicated in the pathogenesis of DCM, including viral infections that often induce myocarditis, cardiac toxins or toxic chemotherapeutic agents, the chronic excessive consumption of alcohol, autoimmune abnormality and mitochondrial, metabolic, endocrinal or nutritional disorders (1,6-9). However, following a thorough review of secondary causes, a substantial portion of DCM cases remain unexplained and such DCM is defined as idiopathic DCM, among which $25-50 \%$ of DCM cases occur in at least two closely related family members, hence termed familial DCM (10). Aggregating evidence has demonstrated that genetic defects play a crucial role in the development of DCM, and mutations in $>60$ genes have been associated with DCM (10-22). Among the DCM-associated genes, the majority encode sarcomeric, Z-disc and cytoskeletal proteines that are responsible for the generation and transmission of contractile force, and are inherited predominantly in an autosomal dominant mode, with the autosomal recessive, X-linked, or mitochondrial mode of 
inheritance less frequent (10). Nevertheless, these established DCM-associated genes only account for less than a third of the examined cases and each gene has a low mutational frequency, with the majority occurring in $<1 \%$ of patients with DCM (23). Therefore, the genetic components underpinning DCM in an overwhelming majority of patients remain to be identified.

Previous studies have underscored the pivotal roles of the cardiac transcription factors in cardiac morphogenesis and the proliferation, specification and differentiation of cardiomyocytes, including the GATA zinc finger-containing transcription factor and the NK homeodomain transcription factor families (24-29); a great number of mutations in GATA binding protein (GATA)4, GATA5, GATA6 and NK2 transcription factor related, locus 5 (NKX2.5) have shown to be been involved in various congenital cardiovascular malformations and arrhythmias in humans, including atrial septal defect, ventricular septal defect, tetralogy of Fallot, double outlets of the right ventricle, endocardial cushion defect, atrial fibrillation and cardiac conduction block (30-64). Furthermore, GATA4, GATA6 and NKX2.5 have also been causally linked to human DCM (16-20). Given that the expression profile and functional characteristics of GATA5 overlap at least in part with those of GATA4, GATA6 and NKX2.5, and that GATA5 physically interacts with NKX2.5, collaborating to synergistically activate several key cardiac target genes, such as the sarcomeric genes encoding $\alpha$-myosin heavy chain, $\beta$-myosin heavy chain, cardiac troponin $\mathrm{C}$ and troponin $\mathrm{I}$, and other genes coding for atrial natriuretic factor (ANF), brain natriuretic peptide and connexin40 $(16,24,27,64-68)$, it is justifiable to make a hypothesis that genetically defective GATA 5 can contribute to the development of DCM.

\section{Materials and methods}

Ethics statement. This study conforms to the principles outlined in the Declaration of Helsinki. The study protocol was reviewed and approved by the local institutional ethics committee of Shanghai Tenth People's Hospital, Tongji University, Shanghai, China. Written informed consent was obtained from all participants or their guardians prior to enrollment in the study.

Study population. Patients affected with idiopathic DCM were recruited from the Han Chinese population. Prior to recruitment, all patients were evaluated by detailed history, physical examination, chest radiography, electrocardiogram, echocardiography and exercise performance testing. Cardiac catheterization, ventricular angiography and myocardial biopsy were performed only if there was a strong clinical indication. Idiopathic DCM was diagnosed according to the criteria established by the World Health Organization/International Society and Federation of Cardiology Task Force on the Classification of Cardiomyopathy: a left ventricular end-diastolic diameter $>27 \mathrm{~mm} / \mathrm{m}^{2}$ and an ejection fraction $<40 \%$ or fractional shortening $<25 \%$ in the absence of abnormal loading conditions, coronary artery disease, congenital heart malformations and other systemic disorders $(17-19,69)$. Patients with concomitant disease that may contribute to heart failure, such as coronary artery disease, congenital heart disease, valvular heart disease, viral myocarditis and essential hypertension, were excluded. Familial DCM was defined when DCM occurred in 2 or more first-degree family relatives. The available family members of the index patients were also included in this study and for the deceased or unavailable relatives, the medical records were reviewed. The control population consisted of ethnicallymatched healthy individuals. Peripheral venous blood samples were obtained from all participants.

Mutational scan of GATA5. Genomic DNA was isolated from the peripheral blood leucocytes of each study subject using the Wizard Genomic DNA Purification kit (Promega, Madison, WI, USA). The coding exons and exon-intron boundaries of the GATA5 gene were sequenced in 130 unrelated patients with idiopathic DCM. When a mutation was identified in an index patient, the available relatives of the mutation carrier and 200 unrelated healthy controls were subsequently genotyped for GATA5. The primer pairs used to amplify the coding regions and splice junction sites of GATA5 by polymerase chain reaction (PCR) were designed as previously described (46). PCR was conducted using HotStar TaqDNA polymerase (Qiagen, Hilden, Germany) on a Veriti Thermal Cycler (Applied Biosystems, Foster, CA, USA) with standard conditions and concentrations of reagents. The amplified product was fractionated on a $1 \%$ agarose gel and then extracted using the QIAquick Gel Extraction kit (Qiagen), as described in a previous study of ours (19). Both strands of each PCR product were sequenced using the BigDye ${ }^{\circledR}$ Terminator version 3.1 Cycle Sequencing kit under an ABI PRISM 3130 XL DNA Analyzer (both from Applied Biosystems). DNA sequences were analyzed using the DNA Sequencing Analysis Software version 5.1 (Applied Biosystems). The identified sequence variation was verifieded by re-sequencing of an independent PCR-generated amplicon from the same subject. Additionally, for an identified variant, the single nucleotide polymorphism (SNP; http://www.ncbi. nlm.nih.gov/SNP) and human gene mutation (HGM; http:// www.hgmd.org) databases were queried to confirm its novelty.

Alignment of multiple amino acid sequences of GATA5 across species. The amino acid sequence of human GATA5 was aligned with that of the chimpanzee, rhesus monkey, dog, cattle, mouse, rat, fowl, zebrafish and frog using the online Muscle program (http://www.ebi.ac.uk/Tools/msa/muscle/).

Functional analysis in silico. The disease-causing potential of a GATA5 sequence variation was predicted by MutationTaster (an online program at http://www.mutationtaster.org), which automatically yields a probability for the variation to be either a pathogenic mutation or a benign polymorphism. Notably, the P-value used here is the probability of the correct prediction (i.e., a value close to 1 indicates a high accuracy of the prediction). Additionally, another online program, PolyPhen-2 (http://genetics.bwh.harvard.edu/pph2), was also used to evaluate the possible effect of an amino acid substitution on the function of GATA5.

Expression plasmids and site-directed mutagenesis. The recombinant expression plasmid, GATA5-pcDNA3.1, was constructed as previously described (46). The reporter plasmid, ANF-luciferase (ANF-luc), which contains the 2,600-bp 5 '-flanking region of the $A N F$ gene, was a kind gift from Dr Ichiro Shiojima at Chiba University School of Medicine, Chiba, Japan. 
Table I. Baseline clinical characteristics of the study participants.

\begin{tabular}{lccc}
\hline Characteristics & Patients $(\mathrm{n}=130)$ & Controls $(\mathrm{n}=200)$ & P-value \\
\hline Age (years) & $56.8 \pm 12.4$ & $57.3 \pm 11.5$ & 0.7085 \\
Male $(\%)$ & $72(55)$ & $110(55)$ & 0.9453 \\
Family history of DCM (\%) & $35(27)$ & $0(0)$ & $<0.0001$ \\
SBP $(\mathrm{mmHg})$ & $114.2 \pm 13.6$ & $125.4 \pm 10.9$ & $<4.7 \pm 7.1$ \\
DBP $(\mathrm{mmHg})$ & $76.5 \pm 8.8$ & $75.8 \pm 9.5$ & $<0.0001$ \\
HR $($ bpm) & $92.4 \pm 11.3$ & $48.1 \pm 6.4$ & $<0.0001$ \\
LVEDD $(\mathrm{mm})$ & $68.2 \pm 8.2$ & $36.2 \pm 6.9$ & $<2.7 \pm 8.0$ \\
LVESD $(\mathrm{mm})$ & $56.5 \pm 7.3$ & & $<0.0001$ \\
LVEF $(\%)$ & $37.2 \pm 10.4$ & NA & $<0.0001$ \\
NYHA function class $(\%)$ & & NA & NA \\
I & $26(20)$ & NA & NA \\
II & $52(40)$ & $40(31)$ & NA \\
III & $12(9)$ & NA & NA \\
\hline
\end{tabular}

DCM, dilated cardiomyopathy; SBP, systolic blood pressure; DBP, diastolic blood pressure; HR, heart rate; LVEDD, left ventricular end-diastolic diameter; LVESD, left ventricular end-systolic diameter; LVEF, left ventricular ejection fraction; NYHA, New York Heart Association; NA, not applicable.

The identified mutation was introduced into the wild-type GATA5 expression plasmid using a QuickChange II XL SiteDirected Mutagenesis kit (Stratagene, La Jolla, CA, USA) with a complementary pair of primers. The full-length cDNA of mutant GATA5 was sequenced to confirm the desired mutation and to exclude any other non-synonymous variations.

Reporter gene assays. HEK-293 cells (from our cell bank) were seeded in 12-well plates and cultured in Dulbecco's modified Eagle's medium supplemented with $10 \%$ fetal calf serum for $24 \mathrm{~h}$ before being transfected with the empty pcDNA3.1 vector, wild-type or mutant GATA5-pcDNA3.1 expression construct along with the Firefly luciferase reporter plasmid. In addition, the Renilla luciferase vector pGL4.75 (hRluc/CMV; Promega) was co-transfected into the cells as an internal control for transfection efficiency. The cells were transfected with $0.4 \mu \mathrm{g}$ of pcDNA3.1, wild-type or mutant GATA5-pcDNA3.1, $1.0 \mu \mathrm{g}$ of ANF-luc, and $0.04 \mu \mathrm{g}$ of pGL4.75 using Lipofectomine 2000 transfection reagent (Invitrogen, Carlsbad, CA, USA). For co-transfection experiments, $0.2 \mu \mathrm{g}$ of wild-type GATA5-pcDNA3.1, $0.2 \mu \mathrm{g}$ of mutant GATA5-pcDNA3.1, $1.0 \mu \mathrm{g}$ of ANF-luc and $0.04 \mu \mathrm{g}$ of pGL4.75 were used. The cells were incubated at $37^{\circ} \mathrm{C}$ and harvested $48 \mathrm{~h}$ after transfection. The luciferase activity of the lysates was measured using the Dual-Luciferase Reporter assay system (Promega) according to the manufacturer's instructions. The activity of the ANF promoter was presented as the fold activation of Firefly luciferase relative to Renilla luciferase. For wild-type or mutant GATA5, a minimum of 3 independent experiments were performed in triplicate.

Statistical analysis. Continuous variables are expressed as the means \pm standard deviation (SD). The Student's unpaired t-test was used to compare the continuous variables between 2 groups. A comparison of the categorical variables between 2 groups was carried out using Pearson's $\chi^{2}$ test. A two-tailed P-value $<0.05$ was considered to indicate a statistically significant difference.

\section{Results}

Baseline clinical characteristics of the study population. A cohort of 130 genetically unrelated patients with idiopathic DCM was clinically investigated in contrast to 200 unrelated control (healthy) individuals. They had no apparent traditional risk factors predisposing to DCM. All the patients presented with the typical DCM phenotype as previously described $(1,17-19,69)$. The control individuals had normal echocardiographic parameters without evidence of structural cardiac diseases. The baseline clinical characteristics of the study population are summarized in Table I.

Novel GATA5 mutation identified. By sequence analysis of the GATA5 gene in the 130 unrelated patients with idiopathic DCM, a heterozygous missense mutation was identified in a patient, with a mutational prevalence of approximately $0.77 \%$. Specifically, a substitution of adenine for guanine in the second nucleotide of codon 240 (c.719G $>$ A), predicting the transition of glycine (G) into aspartic acid (D) at amino acid position 240 (p.G240D) was identified in the index patient from family 1. The sequence chromatograms showing the detected heterozygous GATA5 mutation of c.719G>A compared with its control sequence are shown in Fig. 1. A schematic diagram of GATA5 protein with the identified mutation marked above the structural domains is displayed in Fig. 2. The mutation was neither 


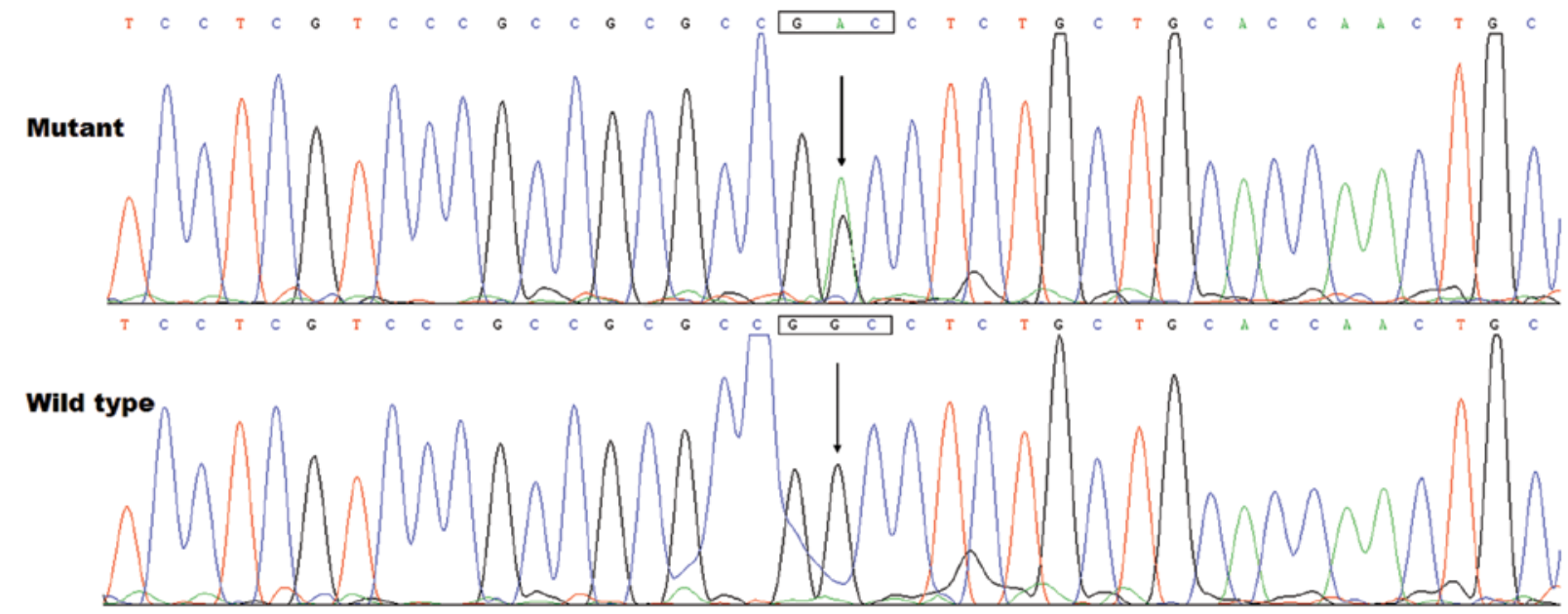

Figure 1. Sequence electropherograms showing the heterozygous GATA5 mutation compared with its control. The arrow points to the heterozygous nucleotides of $\mathrm{G} / \mathrm{A}$ in the proband (mutant) or the homozygous nucleotides of $\mathrm{G} / \mathrm{G}$ in the corresponding control subject (wild-type). The rectangle indicates the nucleotides constituting a codon of GATA5.

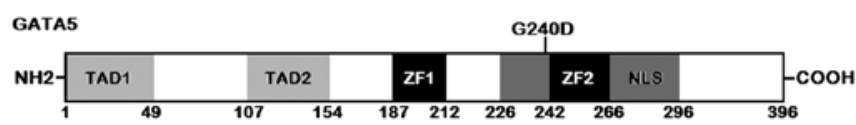

Figure 2. Schematic diagram of GATA5 protein structure with the dilated cardiomyopathy-associated mutation marked. The mutation identified in patients with familial dilated cardiomyopathy is shown above the structural domains. NH2, amino-terminus; TAD, transcriptional activation domain; $\mathrm{ZF}$, zinc finger; NLS, nuclear localization signal; $\mathrm{COOH}$, carboxyl-terminus.

detected in the 200 control subjects nor reported in the public databases for human sequence variations, including the SNP and HGM databases, suggesting that it was a novel mutation. The genetic screening of the family of the proband revealed that the mutation was present in all affected family members alive, but absent in unaffected family members examined. Analysis of the pedigree demonstrated that the mutation co-segregated with DCM transmitted as an autosomal dominant trait in the family with complete penetrance. Besides, the father of the proband (I-1), younger sister (II-6) and younger brother (II-7) also had ventricular septal defect together with second-degree atrioventricular block, paroxismal atrial fibrillation and ventricular septal defect, respectively. The pedigree structure of the family is exhibited in Fig. 3. The phenotypic characteristics and status of GATA5 mutation of the affected family members are provided in Table II.

Alignment of multiple GATA5 protein sequences across species. A cross-species alignment of GATA5 protein sequences revealed that the altered amino acid, p.G240, was completely conserved evolutionarily in various species (Fig. 4).

Disease-causing potential analyzed in silico. The GATA5 sequence variation of c.719G $>$ A was predicted by MutationTaster to be a causative mutation with a P-value of almost 1.0. The corresponding amino acid substitution of p.G240D was also predicted by PolyPhen- 2 to be possibly damaging, with a score of 0.968 (sensitivity, 0.61 ; specificity, 0.93).

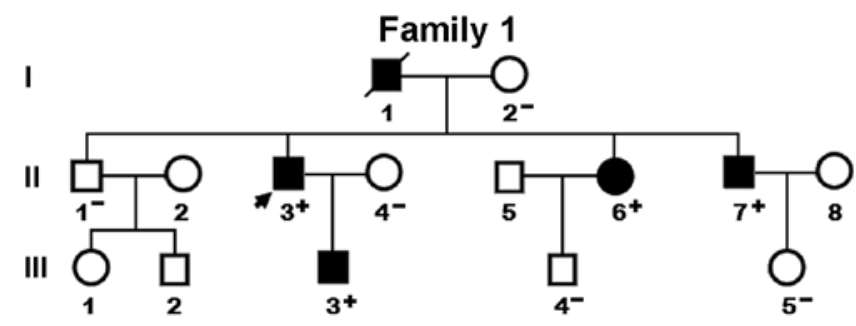

Figure 3. Pedigree structure of the family with dilated cardiomyopathy. Family members are identified by generations and numbers. Square, male family member; circle, female member; symbol with a slash, deceased family member; closed symbol, affected member; open symbol, unaffected member; arrow, proband; +, carrier of the heterozygous mutation; -, non-carrier of the heterozygous mutation.

Diminished transcriptional activity of the GATA5 mutant. The same amount $(0.4 \mu \mathrm{g})$ of wild-type and G240D-mutant GATA5 activated the $A N F$ promoter by $\sim 12$ - and $\sim 2$-fold, respectively (Fig. 5). When the same amount of wild-type GATA5 $(0.2 \mu \mathrm{g})$ was co-transfected with G240D-mutant GATA5 $(0.2 \mu \mathrm{g})$, the induced activation of the $A N F$ promoter was $~ 4-$ fold. These results demonstrate that the G240D-mutant GATA5 has a significantly decreased transcriptional activity compared with its wild-type counterpart.

\section{Discussion}

In the present study, a novel heterozygous GATA5 mutation, p.G240D, was identified in a family with DCM transmitted in an autosomal dominant manner. In the family, the missense mutation co-segregated with DCM with complete penetrance. This sequence variation altered the amino acid that was completely conserved evolutionarily, and was predicted to be a pathogenic mutation by MutationTaster and PolyPhen-2. Functional assays unveiled that the mutant GATA5 was associated with significantly reduced transcriptional activity. These findings demonstrate that the GATA5 loss-of-function mutation can contribute to the development of DCM. 
Table II. Phenotypic characteristics of the affected pedigree members.

\begin{tabular}{lcclcccccc}
\hline Individual & Gender & $\begin{array}{c}\text { Age } \\
(\text { years })\end{array}$ & $\begin{array}{c}\text { Cardiac } \\
\text { phenotype }\end{array}$ & $\begin{array}{c}\text { LVEDD } \\
(\mathrm{mm})\end{array}$ & $\begin{array}{c}\text { LVESD } \\
(\mathrm{mm})\end{array}$ & $\begin{array}{c}\text { LVEF } \\
(\%)\end{array}$ & $\begin{array}{c}\text { LVFS } \\
(\%)\end{array}$ & $\begin{array}{c}\text { ECG } \\
\text { findings }\end{array}$ & $\begin{array}{c}\text { GATA5 } \\
\text { mutation }\end{array}$ \\
\hline I-1 & M & $65^{\mathrm{a}}$ & DCM, VSD & 78 & 66 & 29 & 15 & AVB & NA \\
II-3 & M & 50 & DCM & 75 & 60 & 41 & 20 & & $+/-$ \\
II-6 & F & 47 & DCM & 64 & 50 & 32 & 21 & PAF & $+/-$ \\
II-7 & M & 43 & DCM, VSD & 60 & 47 & 35 & 23 & & $+/-$ \\
III-3 & M & 26 & DCM & 57 & 46 & 19 & 19 & +- \\
\hline
\end{tabular}

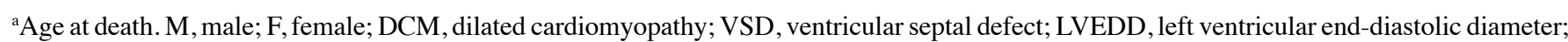
LVESD, left ventricular end-systolic diameter; LVEF, left ventricular ejection fraction; LVFS, left ventricular fractional shortening; AVB, atrioventricular conduction block; PAF, paroxysmal atrial fibrillation; +/-, presence of heterozygous mutation; NA, not available or not applicable.

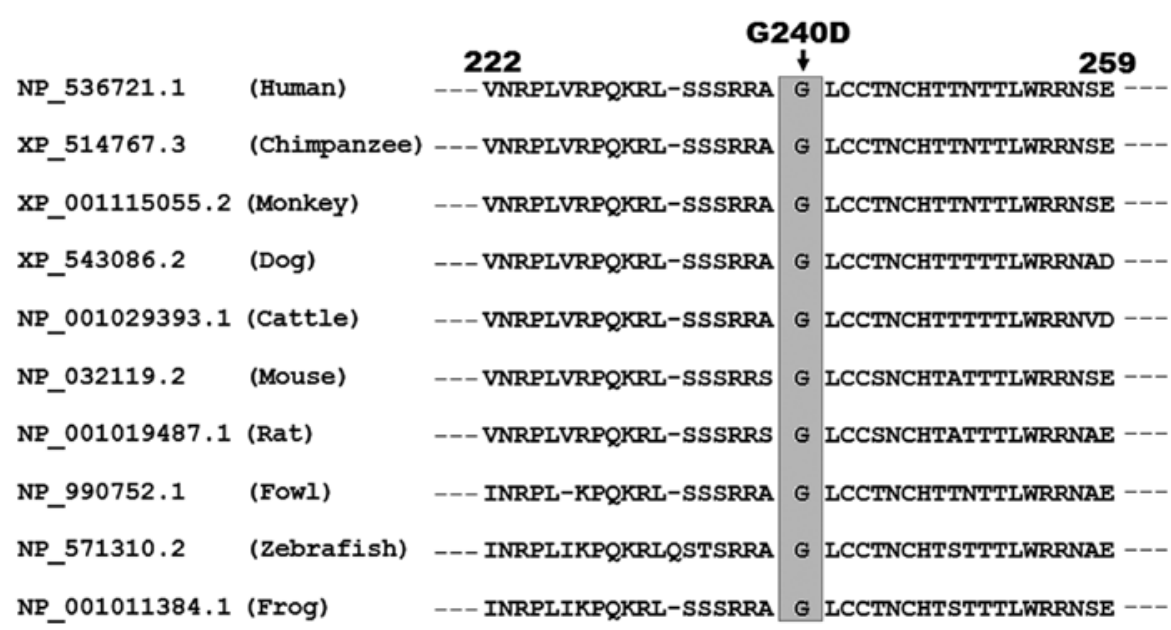

Figure 4. Alignment of multiple GATA5 protein sequences from various species. The altered amino acid of p.G240 is completely conserved evolutionarily across species.

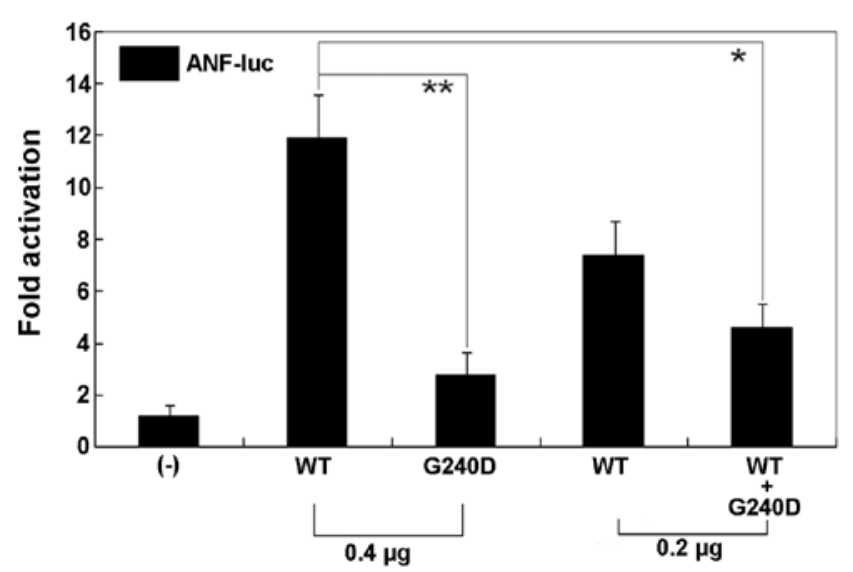

Figure 5. Functional impairment resulting from GATA5 mutation. Activation of atrial natriuretic factor $(A N F)$ promoter driven luciferase reporter in HEK-293 cells by wild-type (WT) or G240D-mutant GATA5, alone or together, showed significantly decreased transcriptional activation by the mutant protein. Experiments were performed in triplicate, and data represent the means \pm standard deviation. ${ }^{*} \mathrm{P}<0.001$ and $^{* *} \mathrm{P}<0.0005$ when compared with wild-type GATA5 $(0.4 \mu \mathrm{g})$.

To date, 6 members of the GATA transcription factor family have been identified in vertebrates and parsed into
2 subfamilies based on their expression patterns. GATA1-3 genes are prominently expressed in hematopoietic cell lineages where they regulate differentiation-specific gene expression in T-lymphocytes, erythroid cells and megakaryocytes; GATA4-6 genes are expressed in various mesoderm- and endoderm-derived tissues such as heart, liver, lung, gonad and gut tissues, where they play critical roles in regulating tissuespecific gene expression (70). In humans, the GATA5 gene was mapped on chromosome 20q13.33 by fluorescence in situ hybridization, which encodes a protein of 396 amino acids (71). The structural domains of GATA5 comprise 2 transcriptional activation domains (TAD1, amino acids 1-49; TAD2, amino acids 107-154), 2 adjacent zinc fingers (ZF1, amino acids 187-212; ZF2, amino acids 242-266) and 1 nuclear localization signal (NLS, amino acids 226-296). The 2 TADs are crucial for the proper transcriptional activity of GATA5. The C-terminal ZF2 is essential for DNA sequence recognition and binding to the consensus motif (T/A)GATA(A/G), within the promoters of target genes; the N-terminal $\mathrm{ZF} 1$ is responsible for sequence specificity and stability of protein-DNA binding, and both ZFs can also interact directly with other regulatory proteins. The NLS is required for the sub-cellular trafficking and nuclear distribution of GATA5 (44). The GATA5 mutation of p.G240D identified in this study is located in the NLS, and 
thus may be expected to influence the transcriptional activity of GATA5 by interfering with the nuclear localization of GATA5.

It has been validated that GATA5 is an upstream mediator of multiple genes expressed during cardiogenesis, including the ANF gene (72). Hence, the functional effect of the GATA5 mutation may be ascertained at least in part by analyzing the transcriptional activation of the $A N F$ promoter in appropriate cells. In the present study, the functional characteristics of the novel GATA5 mutation (p.G240D) identified in the patients with familial DCM were explored by transactivational analysis in HEK-293 cells and the results unveiled that the G240Dmutant GATA5 had a significantly reduced transcriptional activity. These data indicate that haploinsufficiency or dominant-negative effect resulted from GATA5 mutation is likely to be an alternative molecular mechanism underlying DCM.

The findings that genetically defective GATA5 confers enhanced susceptibility to DCM may be partially ascribed to the abnormal development of the myocardium. In zebrafish, the depletion of the GATA5 transcription factor has been shown to lead to cardiac morphogenetic defects and the loss of myocardial tissue. In addition, in zebrafish, the Gata5 and Gata6 genes are redundant for the specification of cardiomyocytes. Embryos depleted of these two gene products were heartless and restoring either gene product was sufficient to rescue cardiomyocyte specification. By contrast, embryos depleted of Gata4 and Gata6, or Gata4 and Gata5, developed defective heart tubes, suggesting that a specific pair of GATA transcription factors is essential for cardiomyocyte specification (68). Moreover, as a negative regulator of myocardial proliferative growth in zebrafish embryos, the GRL transcription factor diminishes cardiomyocyte volume and inhibits cell proliferation, resulting in a marked reduction in heart size. These GRL-induced cardiac effects were counterbalanced by the transcriptional activator Gata5 but not Gata4, which promotes cardiomyocyte expansion in the embryo, suggesting that GRL negatively regulates embryonic heart growth by opposing Gata5 (73). In mice, the targeted deletion of Gata5 has been shown to result in hypoplastic hearts and partially penetrant bicuspid aortic valves (74). Furthermore, GATA5 interacts with GATA4 and GATA6 and cooperatively regulates cardiac myocyte proliferation $(65,66)$. In a new mouse model with Gata5-mutant allele lacking exons 2 and 3, although Gata5(-/-) mice were viable, Gata4(+/-)5(-/-) mutants died at mid-gestation and exhibited profound cardiovascular defects, including abnormalities of cardiomyocyte proliferation and cardiac chamber maturation (66). In double-gene deletion mouse models, compound Gata4/Gata5 and Gata5/Gata6 mutants died embryonically or perinatally due to severe congenital heart defects. Almost all Gata4(+/-)Gata5(+/-) mutant embryos had double outlet right ventricles and large ventricular septal defects. The compound loss of a Gata5 and a Gata6 allele also led to double outlet right ventricles associated with subaortic ventricular septal defects (65). Taken together, these results highlight the existence of important genetic interactions between GATA5 and the two other cardiac GATA factors in cardiovascular development.

In humans, a great number of GATA5 mutations have been previously associated with various congenital cardiovascular deformities, including atrial septal defect, ventricular septal defect, tetralogy of Fallot, double outlet right ventricle, aortic stenosis, patent ductus arteriosus and bicuspid aortic valve (40-44). In the present study, all the mutation carriers had DCM, but only 2 mutation carriers also had ventricular septal defect. The pronunced discrepancy in the GATA5-related phenotypes may be explained by one or more of the following reasons. Firstly, since some developmental anomalies in cardiac structure may be restored spontaneously, we cannot rule out the possibility that some mutation carriers had minor cardiac septal defects that healed on their own soon after birth. In addition, distinct genetic backgrounds may partially account for the phenotypic heterogeneity. Finally, mutations such as p.G240D may be merely a genetic modifier that confers vulnerability to the diseases, rather than a direct cause, other genetic determinants and environmental risk factors may be required for the onset of congenital heart diseases.

In conclusion, to the best of our knowledge, this is the first study on the association of GATA5 loss-of-function mutation with increased susceptibility to human DCM, which provides novel insight into the molecular mechanisms responsible for DCM, suggesting a potential molecular target for the antenatal prevention and gene-specific treatment of DCM.

\section{Acknowledgements}

The authors are extremely thankful to the participants for their dedication to the study. This study was supported in part by grants from the National Natural Science Fund of China (81270161,81271927 and 81370301), the Natural Science Fund of Shanghai, China (13ZR1438400 and 14ZR1438000), the Experimental Animal Fund of Shanghai, China (12140902800), and the Key Program of Basic Research of Shanghai, China (14JC1405500).

\section{References}

1. Maron BJ, Towbin JA, Thiene G, Antzelevitch C, Corrado D, Arnett D, Moss AJ, Seidman CE and Young JB: Contemporary definitions and classification of the cardiomyopathies: an American Heart Association Scientific Statement from the Council on Clinical Cardiology, Heart Failure and Transplantation Committee; Quality of Care and Outcomes Research and Functional Genomics and Translational Biology Interdisciplinary Working Groups; and Council on Epidemiology and Prevention. Circulation 113: 1807-1816, 2006.

2. Abdo AS, Kemp R, Barham J and Geraci SA: Dilated cardiomyopathy and role of antithrombotic therapy. Am J Med Sci 339: 557-560, 2010.

3. Aleksova A, Carriere C, Zecchin M, Barbati G, Vitrella G, Di Lenarda A and Sinagra G: New-onset left bundle branch block independently predicts long-term mortality in patients with idiopathic dilated cardiomyopathy: data from the Trieste Heart Muscle Disease Registry. Europace 16: 1450-1459, 2014.

4. Disertori M, Quintarelli S, Mazzola S, Favalli V, Narula N and Arbustini E: The need to modify patient selection to improve the benefits of implantable cardioverter-defibrillator for primary prevention of sudden death in non-ischaemic dilated cardiomyopathy. Europace 15: 1693-1701, 2013.

5. Koutalas E, Kanoupakis E and Vardas P: Sudden cardiac death in non-ischemic dilated cardiomyopathy: a critical appraisal of existing and potential risk stratification tools. Int J Cardiol 167: 335-341, 2013.

6. Gaaloul I, Riabi S, Harrath R, Hunter T, Hamda KB, Ghzala AB, Huber S and Aouni M: Coxsackievirus B detection in cases of myocarditis, myopericarditis, pericarditis and dilated cardiomyopathy in hospitalized patients. Mol Med Rep 10: 2811-2818, 2014.

7. Xu HF, Ding YJ, Zhang ZX, Wang ZF, Luo CL, Li BX, Shen YW, Tao LY and Zhao ZQ: MicroRNA-21 regulation of the progression of viral myocarditis to dilated cardiomyopathy. Mol Med Rep 10: 161-168, 2014. 
8. Kong Q, Li X, Wu W, Yang F, Liu Y, Lai W, Pan X, Gao M and Xue Y: Increased circulating T-helper 22 cells in patients with dilated cardiomyopathy. Mol Med Rep 10: 359-364, 2014.

9. Yoshikawa T: Contribution of acquired factors to the pathogenesis of dilated cardiomyopathy. -The cause of dilated cardiomyopathy: genetic or acquired? (Acquired-Side). Circ J 75: 1766-1773, 2011

10. McNally EM, Golbus JR and Puckelwartz MJ: Genetic mutations and mechanisms in dilated cardiomyopathy. J Clin Invest 123: 19-26, 2013.

11. Wahbi K, Béhin A, Bécane HM, Leturcq F, Cossée M, Laforêt P, Stojkovic T, Carlier P, Toussaint M, Gaxotte V, Cluzel P, Eymard B and Duboc D: Dilated cardiomyopathy in patients with mutations in anoctamin 5. Int J Cardiol 168: 76-79, 2013.

12. Ruppert V, Meyer T, Richter A, Maisch B and Pankuweit S; German Competence Network of Heart F: Identification of a missense mutation in the melusin-encoding ITGB1BP2 gene in a patient with dilated cardiomyopathy. Gene 512: 206-210, 2013.

13. Pankuweit S1, Ruppert V, Jónsdóttir T, Müller HH and Meyer T; German Competence Network of Heart Failure: The HLA class II allele DQB1 0309 is associated with dilated cardiomyopathy. Gene 531: 180-183, 2013.

14. Agrawal PB, Pierson CR, Joshi M, Liu X, Ravenscroft G, Moghadaszadeh B, Talabere T, Viola M, Swanson LC, Haliloğlu G, Talim B, Yau KS, Allcock RJ, Laing NG, Perrella MA and Beggs AH: SPEG interacts with myotubularin and its deficiency causes centronuclear myopathy with dilated cardiomyopathy. Am J Hum Genet 95: 218-226, 2014

15. Matsa LS, Sagurthi SR, Ananthapur V, Nalla S and Nallari P: Endothelin 1 gene as a modifier in dilated cardiomyopathy. Gene 548: 256-262, 2014

16. Costa MW, Guo G, Wolstein O, Vale M, Castro ML, Wang L, Otway R, Riek P, Cochrane N, Furtado M, Semsarian C, Weintraub RG, Yeoh T, Hayward C, Keogh A, Macdonald P, Feneley M, Graham RM, Seidman JG, Seidman CE, Rosenthal N, Fatkin D and Harvey RP: Functional characterization of a novel mutation in NKX2-5 associated with congenital heart disease and adult-onset cardiomyopathy. Circ Cardiovasc Genet 6 : 238-247, 2013

17. Li RG, Li L, Qiu XB, Yuan F, Xu L, Li X, Xu YJ, Jiang WF, Jiang JQ, Liu X, Fang WY, Zhang M, Peng LY, Qu XK and Yang YQ: GATA4 loss-of-function mutation underlies familial dilated cardiomyopathy. Biochem Biophys Res Commun 439: 591-596, 2013

18. Zhao L, Xu JH, Xu WJ, Yu H, Wang Q, Zheng HZ, Jiang WF, Jiang JF and Yang YQ: A novel GATA4 loss-of-function mutation responsible for familial dilated cardiomyopathy. Int J Mol Med 33: 654-660, 2014.

19. Li J, Liu WD, Yang ZL, Yuan F, Xu L, Li RG and Yang YQ: Prevalence and spectrum of GATA4 mutations associated with sporadic dilated cardiomyopathy. Gene 548: 174-181, 2014.

20. Xu L, Zhao L, Yuan F, Jiang WF, Liu H, Li RG, Xu YJ, Zhang M, Fang WY, Qu XK, Yang YQ and Qiu XB: GATA6 loss-offunction mutations contribute to familial dilated cardiomyopathy. Int J Mol Med 34: 1315-1322, 2014.

21. Dhandapany PS, Razzaque MA, Muthusami U, Kunnoth S Edwards JJ, Mulero-Navarro S, Riess I, Pardo S, Sheng J, Rani DS, Rani B, Govindaraj P, Flex E, Yokota T, Furutani M, Nishizawa T, Nakanishi T, Robbins J, Limongelli G, Hajjar RJ, Lebeche D, Bahl A, Khullar M, Rathinavel A, Sadler KC, Tartaglia M, Matsuoka R, Thangaraj K and Gelb BD: RAF1 mutations in childhood-onset dilated cardiomyopathy. Nat Genet 46: 635-639, 2014.

22. Roh JI, Cheong C, Sung YH, Lee J, Oh J, Lee BS, Lee JE, Gho YS, Kim DK, Park CB, Lee JH, Lee JW, Kang SM and Lee HW: Perturbation of NCOA6 leads to dilated cardiomyopathy. Cell Rep 8: 991-998, 2014

23. Flack E and Kannankeril PJ: The genetics of dilated cardiomyopathy. Heart Rhythm 9: 397-398, 2012.

24. Pikkarainen S, Tokola H, Kerkelä R and Ruskoaho H: GATA transcription factors in the developing and adult heart. Cardiovasc Res 63: 196-207, 2004.

25. Oka T, Xu J and Molkentin JD: Re-employment of developmental transcription factors in adult heart disease. Semin Cell Dev Biol 18: 117-131, 2007.

26. Kikuchi K, Holdway JE, Werdich AA, Anderson RM, Fang Y, Egnaczyk GF, Evans T, Macrae CA, Stainier DY and Poss KD: Primary contribution to zebrafish heart regeneration by gata4(+) cardiomyocytes. Nature 464: 601-605, 2010.
27. Akazawa Hand Komuro I: Cardiac transcription factor Csx/ $\mathrm{Nkx2-5:}$ Its role in cardiac development and diseases. Pharmacol Ther 107: 252-268, 2005.

28. Kasahara A, Cipolat S, Chen Y, Dorn GW II and Scorrano L: Mitochondrial fusion directs cardiomyocyte differentiation via calcineurin and Notch signaling. Science 342: 734-737, 2013.

29. Cai H, Katoh-Kurasawa M, Muramoto T, Santhanam B, Long Y, Li L, Ueda M, Iglesias PA, Shaulsky G and Devreotes PN: Nucleocytoplasmic shuttling of a GATA transcription factor functions as a development timer. Science 343: 1249531, 2014.

30. Garg V, Kathiriya IS, Barnes R, Schluterman MK, King IN, Butler CA, Rothrock CR, Eapen RS, Hirayama-Yamada K, Joo K, Matsuoka R, Cohen JC and Srivastava D: GATA4 mutations cause human congenital heart defects and reveal an interaction with TBX5. Nature 424: 443-447, 2003.

31. Rajagopal SK, Ma Q, Obler D, Shen J, Manichaikul A, TomitaMitchell A, Boardman K, Briggs C, Garg V, Srivastava D, Goldmuntz E, Broman KW, Benson DW, Smoot LB and Pu WT: Spectrum of heart disease associated with murine and human GATA4 mutation. J Mol Cell Cardiol 43: 677-685, 2007.

32. Yang YQ, Li L, Wang J, Liu XY, Chen XZ, Zhang W, Wang XZ, Jiang JQ, Liu X and Fang WY: A novel GATA4 loss-of-function mutation associated with congenital ventricular septal defect. Pediatr Cardiol 33: 539-546, 2012

33. Wang J, Sun YM and Yang YQ: Mutation spectrum of the GATA4 gene in patients with idiopathic atrial fibrillation. Mol Biol Rep 39: 8127-8135, 2012

34. Yang YQ, Wang J, Liu XY, Chen XZ, Zhang W and Wang XZ: Mutation spectrum of GATA4 associated with congenital atrial septal defects. Arch Med Sci 9: 976-983, 2013.

35. Yang YQ, Gharibeh L, Li RG, Xin YF, Wang J, Liu ZM, Qiu XB, Xu YJ, Xu L, Qu XK, Liu X, Fang WY, Huang RT, Xue S and Nemer G: GATA4 loss-of-function mutations underlie familial tetralogy of fallot. Hum Mutat 34: 1662-1671, 2013.

36. Wang E, Sun S, Qiao B, Duan W, Huang G, An Y, Xu S, Zheng Y, $\mathrm{Su} \mathrm{Z}, \mathrm{Gu} \mathrm{X}$, Jin $\mathrm{L}$ and Wang $\mathrm{H}$ : Identification of functional mutations in GATA4 in patients with congenital heart disease. PLoS One 8: e62138, 2013.

37. Xiang R, Fan LL, Huang H, Cao BB, Li XP, Peng DQ and Xia K: A novel mutation of GATA4 (K319E) is responsible for familial atrial septal defect and pulmonary valve stenosis. Gene 534: 320-323, 2014.

38. Posch MG, Boldt LH, Polotzki M, Richter S, Rolf S, Perrot A, Dietz R, Ozcelik C and Haverkamp W: Mutations in the cardiac transcription factor GATA4 in patients with lone atrial fibrillation. Eur J Med Genet 53: 201-203, 2010.

39. Jiang JQ, Shen FF, Fang WY, Liu X and Yang YQ: Novel GATA4 mutations in lone atrial fibrillation. Int J Mol Med 28: 1025-1032, 2011.

40. Jiang JQ, Li RG, Wang J, Liu XY, Xu YJ, Fang WY, Chen XZ, Zhang W, Wang XZ and Yang YQ: Prevalence and spectrum of GATA5 mutations associated with congenital heart disease. Int J Cardiol 165: 570-573, 2013.

41. Wei D, Bao H, Zhou N, Zheng GF, Liu XY and Yang YQ: GATA5 loss-of-function mutation responsible for the congenital ventriculoseptal defect. Pediatr Cardiol 34: 504-511, 2013.

42. Wei D, Bao H, Liu XY, Zhou N, Wang Q, Li RG, Xu YJ and Yang YQ: GATA5 loss-of-function mutations underlie tetralogy of fallot. Int J Med Sci 10: 34-42, 2013.

43. Huang RT, Xue S, Xu YJ, Zhou M and Yang YQ: Somatic GATA5 mutations in sporadic tetralogy of Fallot. Int J Mol Med 33: 1227-1235, 2014

44. Shi LM, Tao JW, Qiu XB, Wang J, Yuan F, Xu L, Liu H, Li RG, Xu YJ, Wang Q, Zheng HZ, Li X, Wang XZ, Zhang M, Qu XK and Yang YQ: GATA5 loss-of-function mutations associated with congenital bicuspid aortic valve. Int J Mol Med 33: 1219-1226, 2014.

45. Yang YQ, Wang J, Wang XH, Wang Q, Tan HW, Zhang M, Shen FF, Jiang JQ, Fang WY and Liu X: Mutational spectrum of the GATA5 gene associated with familial atrial fibrillation. Int J Cardiol 157: 305-307, 2012

46. Wang XH, Huang CX, Wang Q, Li RG, Xu YJ, Liu X, Fang WY and Yang YQ: A novel GATA5 loss-of-function mutation underlies lone atrial fibrillation. Int J Mol Med 31: 43-50, 2013.

47. Kodo K, Nishizawa T, Furutani M, Arai S, Yamamura E, Joo K, Takahashi T, Matsuoka R and Yamagishi H: GATA6 mutations cause human cardiac outflow tract defects by disrupting semaphorin-plexin signaling. Proc Natl Acad Sci USA 106: 13933-13938, 2009. 
48. Lin X, Huo Z, Liu X, Zhang Y, Li L, Zhao H, Yan B, Liu Y, Yang Y and Chen YH: A novel GATA6 mutation in patients with tetralogy of Fallot or atrial septal defect. J Hum Genet 55: 662-667, 2010

49. Zheng GF, Wei D, Zhao H, Zhou N, Yang YQ and Liu XY: A novel GATA6 mutation associated with congenital ventricular septal defect. Int J Mol Med 29: 1065-1071, 2012.

50. Wang J, Luo XJ, Xin YF, Liu Y, Liu ZM, Wang Q, Li RG, Fang WY, Wang XZ and Yang YQ: Novel GATA6 mutations associated with congenital ventricular septal defect or tetralogy of fallot. DNA Cell Biol 31: 1610-1617, 2012.

51. Huang RT, Xue S, Xu YJ and Yang YQ: Somatic mutations in the GATA6 gene underlie sporadic tetralogy of Fallot. Int J Mol Med 31: 51-58, 2013.

52. Wang X, Ji W, Wang J, Zhao P, Guo Y, Xu R, Chen S and Sun K: Identification of two novel GATA6 mutations in patients with nonsyndromic conotruncal heart defects. Mol Med Rep 10 743-748, 2014.

53. Yang YQ, Wang XH, Tan HW, Jiang WF, Fang WY and Liu X: Prevalence and spectrum of GATA6 mutations associated with familial atrial fibrillation. Int J Cardiol 155: 494-496, 2012.

54. Yang YQ, Li L, Wang J, Zhang XL, Li RG, Xu YJ, Tan HW, Wang XH, Jiang JQ, Fang WY and Liu X: GATA6 loss-offunction mutation in atrial fibrillation. Eur J Med Genet 55: 520-526, 2012

55. Li J, Liu WD, Yang ZL and Yang YQ: Novel GATA6 loss-offunction mutation responsible for familial atrial fibrillation. Int J Mol Med 30: 783-790, 2012.

56. Moak JP, Maron BJ, Seidman CE and Seidman JG: Congenital heart disease caused by mutations in the transcription factor NKX2-5. Science 281: 108-111, 1998.

57. Guntheroth W, Chun L, Patton KK, Matsushita MM, Page RL and Raskind WH: Wenckebach periodicity at rest that normalizes with tachycardia in a family with a NKX2.5 mutation. Am J Cardiol 110: 1646-1650, 2012.

58. Perera JL, Johnson NM, Judge DP and Crosson JE: Novel and highly lethal NKX2.5 missense mutation in a family with sudden death and ventricular arrhythmia. Pediatr Cardiol 35: 1206-1212, 2014.

59. Izumi K, Noon S, Wilkens A and Krantz ID: NKX2.5 mutation identification on exome sequencing in a patient with heterotaxy. Eur J Med Genet 57: 558-561, 2014.

60. Qu XK, Qiu XB, Yuan F, Wang J, Zhao CM, Liu XY, Zhang XL, Li RG, Xu YJ, Hou XM, Fang WY, Liu X and Yang YQ: A novel NKX2.5 loss-of-function mutation associated with congenital bicuspid aortic valve. Am J Cardiol 114: 1891-1895, 2014.

61. Xie WH, Chang C, Xu YJ, Li RG, Qu XK, Fang WY, Liu X and Yang YQ: Prevalence and spectrum of Nkx2.5 mutations associated with idiopathic atrial fibrillation. Clinics (Sao Paulo) 68: $777-784,2013$
62. Huang RT, Xue S, Xu YJ, Zhou M and Yang YQ: A novel NKX2.5 loss-of-function mutation responsible for familial atrial fibrillation. Int J Mol Med 31: 1119-1126, 2013.

63. Yu H, Xu JH, Song HM, Zhao L, Xu WJ, Wang J, Li RG, Xu L, Jiang WF, Qiu XB, Jiang JQ, Qu XK, Liu X, Fang WY, Jiang JF and Yang YQ: Mutational spectrum of the NKX2-5 gene in patients with lone atrial fibrillation. Int J Med Sci 11: 554-563, 2014.

64. McCulley DJ and Black BL: Transcription factor pathways and congenital heart disease. Curr Top Dev Biol 100: 253-277, 2012.

65. Laforest B and Nemer M: GATA5 interacts with GATA4 and GATA6 in outflow tract development. Dev Biol 358: 368-378, 2011.

66. Singh MK, Li Y, Li S, Cobb RM, Zhou D, Lu MM, Epstein JA, Morrisey EE and Gruber PJ: Gata4 and Gata5 cooperatively regulate cardiac myocyte proliferation in mice. J Biol Chem 285 1765-1772, 2010

67. Haworth KE, Kotecha S, Mohun TJ and Latinkic BV: GATA4 and GATA5 are essential for heart and liver development in Xenopus embryos. BMC Dev Biol 8: 74, 2008.

68. Holtzinger A and Evans T: Gata5 and Gata6 are functionally redundant in zebrafish for specification of cardiomyocytes. Dev Biol 312: 613-622, 2007.

69. Elliott P, O'Mahony C, Syrris P, Evans A, Rivera Sorensen C, Sheppard MN, Carr-White G, Pantazis A and McKenna WJ: Prevalence of desmosomal protein gene mutations in patients with dilated cardiomyopathy. Circ Cardiovasc Genet 3: 314-322, 2010.

70. Molkentin JD: The zinc finger-containing transcription factors GATA- $4,-5$, and -6 . Ubiquitously expressed regulators of tissuespecific gene expression. J Biol Chem 275: 38949-38952, 2000.

71. Nemer G, Qureshi ST, Malo D and Nemer M: Functional analysis and chromosomal mapping of Gata5, a gene encoding a zinc finger DNA-binding protein. Mamm Genome 10: 993-999, 1999.

72. McBride K and Nemer M: Regulation of the ANF and BNP promoters by GATA factors: lessons learned for cardiac transcription. Can J Physiol Pharmacol 79: 673-681, 2001.

73. Jia H, King IN, Chopra SS, Wan H, Ni TT, Jiang C, Guan X, Wells S, Srivastava D and Zhong TP: Vertebrate heart growth is regulated by functional antagonism between Gridlock and Gata5. Proc Natl Acad Sci USA 104: 14008-14013, 2007.

74. Laforest B, Andelfinger G and Nemer M: Loss of Gata5 in mice leads to bicuspid aortic valve. J Clin Invest 121: 2876-2887, 2011. 